\title{
Properties and Components of the Floury and Sugary Mutant Rice Cultivars Developed in
} the Hokuriku Region

\author{
Noriyuki Homma $^{1 *}$, Keiko Morohashi ${ }^{1}$, Youichi Yoshin ${ }^{1}$, Heitarou HosokawA ${ }^{1}$ and Kiyoyuki MiURA ${ }^{2}$ \\ ${ }^{1}$ Food Research Center, Niigata Agricultural Research Institute, 2-25 Shinei-cho, Kamo-shi, 959-1381, Japan \\ ${ }^{2}$ Hokuriku Research Center, National Agricultural Research Center, 1-2-1 inada, Jouetu-shi, 943-0193, Japan
}

Received April 14, 2005; Accepted May 8, 2006

This paper describes the features of new characteristic rice cultivars developed in the Hokuriku region, especially Hokuriku 166 (floury mutant rice) and Hokuriku 169 (sugary mutant rice), in comparison with Koshihikari. Using Hokuriku 166, it is easy to make fine rice flour because the starch granules for this cultivar are globular and small. Therefore, this cultivar is popular because it is easy to handle. Hokuriku 169 has a high proportion of bran and high $\gamma$-aminobutyric acid (GABA) content. The fineness of Hokuriku 166 rice flour and the component parts of Hokuriku 169 are promising as raw material for processing.

Keywords: new characteristic rice, floury mutant rice, sugary mutant rice, $\boldsymbol{\gamma}$-aminobutyric acid (GABA), particle size

\section{Introduction}

Japan has the appropriate climate for large-scale rice production; however, consumption is declining. Recently, for the purpose of increasing consumption and promoting the utilization of whole rice for purposes other than as a staple food, various kinds of new characteristic rice cultivars have been developed. New characteristic rice cultivars, including low-amylose rice, high-amylose rice, giantgrain rice, waxy-rice (Ohtsubo et al., 1988; Yamada et al., 1993; Toyoshima et al., 1994, 1999), and the components, structures and features of the starch have been studied in detail (Arisaka \& Yoshii, 1994; Fuwa et al., 1994; Mizukami et al., 1996; Kuno et al., 2000; Noda et al., 2003; Wong et al., 2003). Regarding the properties of these new characteristic rice cultivars produced in the Hokuriku region, various reports have been published (Kobayashi et al., 1990ab, 1992, 1998; Uehara et al., 1995ab, 1997). However, further data must be accumulated concerning their respective details, in order to determine the proper application technology for each. Therefore, this paper presents the scientific properties and features of Hokuriku 166 (floury mutant rice) and Hokuriku 169 (sugary mutant rice), produced in the Hokuriku region, in comparison with an ordinary nonglutinous rice (Koshihikari).

\section{Materials and Methods}

Rough samples of Hokuriku 166 and 169 were obtained from the Hokuriku National Agricultural Experiment Station. In all measurements except for that of $\gamma$-aminobutyric acid (GABA) content, brown rice samples were polished until the yield of 100 to $70 \%$, w/w, using a grain

* To whom correspondence should be addressed.

E-mail: nhonma@ari.pref.niigata.jp testing mill (SATAKE, Higashi-Hiroshima, Japan) and then pulverized using a Cyclotec 1093 sample mill (FOSS Tecator AB, Hoganas, Sweden). The weight ratio of each particle size was determined using the Ro-Tap testing sieve shaker (60, 100, 150, 200, 250 mesh). Only for the measurement of GABA content, brown rice grains were soaked in water $\left(25^{\circ} \mathrm{C}\right)$ and then pulverized using the same method after freeze drying (24 hours).

Values of the chemical constituents of rice flours were determined by the standard methods with slight modifications. Each value is shown as a dry matter conversion. Moisture content of rice flour was measured using an ovendry method that included drying for 2 hours at $135^{\circ} \mathrm{C}$. The protein content of rice flour was estimated from nitrogen measured by the Kjeldahl method using 5.95 as conversion coefficient. Crude fat content was measured by the Soxhlet apparatus extractor. Amylose content of the rice flour was estimated by the iodine colorimetric method (Juliano, 1971).

For the measurement of carbohydrate, rice flour $(0.1 \mathrm{~g})$ was mixed with $52 \% \mathrm{HClO}_{4}$ at $4{ }^{\circ} \mathrm{C}$ for 12 hours, and samples for measurement of free sugar and low-molecular free sugar were mixed with distilled water and $80 \%$ ethanol, respectively, for 15 minutes. Subsequently, these suspensions were centrifuged at $3,000 \times \mathrm{g}$ for $10 \mathrm{~min}$. The quantity of carbohydrate, free sugar, and low-molecular free sugar in the supernatant was respectively measured by the phenol sulfuric acid method (Dubois et al., 1956). The percentage of damaged starch in rice flour was estimated by the acid-resolvability method (Arisaka, 1994).

For the measurement of GABA content, freeze dried and pulverized samples (5g) were homogenized and extracted with $20 \mathrm{~mL}$ of $75 \%$ ethanol for $20 \mathrm{~min}$ at $80^{\circ} \mathrm{C}$ three times. All of the extracts were evaporated to dryness in 
air and dissolved in $10 \mathrm{~mL}$ of $0.02 \mathrm{~N} \mathrm{HCl}$, and then centrifuged at $10,000 \times \mathrm{g}$ for $20 \mathrm{~min}$ to remove the precipitate. The supernatant was clarified through a filter unit (pore size $0.45 \mu \mathrm{m}$, hydrophilic) and was subjected to GABA analysis on a Amino Acid Analyzer (L-8800, HITACHI, Hitachi, Japan).

Pasting properties of each rice flour sample were characterized using Viscograph (BRABENDER, Duisburg, Germany). Rice flour that passed through 50 mesh was mixed with water (made to $8 \%$ moisture) to a final weight of 500 $\mathrm{g}$, and the slurry was heated from 30 to $96^{\circ} \mathrm{C}$ at a rate of $1.5^{\circ} \mathrm{C} / \mathrm{min}$ (speed of $75 \mathrm{rpm}$ ), held at $96^{\circ} \mathrm{C}$ for $10 \mathrm{~min}$ and cooled to $30^{\circ} \mathrm{C}$ at a same rate.

The shapes of cross section and particles (through 250 mesh) of the rice flours were observed using a scanning electron microscope (SEMEDX Type N, HITACHI, Hitachi, Japan) at an accelerating voltage of $10-15 \mathrm{KV}$.

\section{Results and Discussion}

Chemical components The moisture, protein, and crude fat contents are summarized in Table 1. Regarding these chemical characteristics, it is shown that Hokuriku 166 resembles Koshihikari, but that Hokuriku 169 is rather different. This seems to be due to a difference in the shape of the grains and the proportion of bran to endosperm. There is little difference in moisture content between brown and polished rice. In contrast, the protein and crude fat contents are gradually decreased with the degree of polishing; therefore, it seems that these components are primarily located on the exterior of the grain. These tendencies are similar to those reported previously

Table 1. Chemical components of milled rice.

\begin{tabular}{lcrrrr}
\hline & \begin{tabular}{c} 
Degree of \\
rice \\
\cline { 3 - 6 }
\end{tabular} & \multicolumn{4}{c}{ Content (\%) } \\
\cline { 3 - 6 } & polishing & Moisture & Protein & Crude \\
& 100 & 13.1 & 7.2 & 3.1 & Amylose \\
\hline Koshihikari & 90 & 13.5 & 6.1 & 0.8 & 13.8 \\
& 80 & 13.2 & 5.1 & 0.1 & 16.6 \\
& 70 & 12.9 & 4.6 & 0.1 & 16.1 \\
\hline Hokuriku 166 & 100 & 13.6 & 8.6 & 3.1 & 13.6 \\
& 90 & 13.9 & 7.6 & 1.6 & 15.1 \\
& 80 & 13.8 & 7.1 & 0.6 & 15.1 \\
& 70 & 13.6 & 6.6 & 0.5 & 15.2 \\
\hline Hokuriku 169 & 100 & 11.6 & 9.1 & 6.5 & 8.1 \\
& 90 & 11.7 & 8.6 & 4.8 & 9.2 \\
& 80 & 11.9 & 7.9 & 3.5 & 10.2 \\
& 70 & 11.6 & 7.3 & 2.4 & 10.2 \\
\hline
\end{tabular}

(Villareal et al., 1991; Ohtsubo, 1995). Contrastingly, the amylose content increases with polishing, and Hokuriku 169 contains less amylose than the other two cultivars. It is assumed that this difference is based on differences in the structure and components of milled rice.

The ratios of carbohydrate, free sugar, low-molecular free sugar and damaged starch are summarized in Table 2. The proportion of carbohydrate is equally high in all three samples, and a larger quantity of free sugar and damaged starch was observed in Hokuriku 169 than in the other two cultivars. The quantity of damaged starch was higher in Koshihikari than in Hokuriku 166.

As shown in Fig. 1, the GABA contents in the soaked cultivars were clearly higher at each time point than those in rice grains before soaking. The GABA contents of Koshihikari and Hokuriku 166 soaked for one hour increased 2-fold, whereas the GABA content of Hokuriku 169 rapidly increased 3-fold after soaking for 24 hours. After soaking in water for 24 hours, the GABA contents of Hokuriku 166 and 169 increased 3-fold.

Distribution of particle size The distributions of par-

Table 2. Chemical properties of milled rice.

\begin{tabular}{lcccc}
\hline & $\begin{array}{c}\text { Carbohydrate } \\
(\%)\end{array}$ & $\begin{array}{c}\text { Free } \\
\text { sugar } \\
(\%)\end{array}$ & $\begin{array}{c}\text { molecular } \\
\text { free sugar } \\
(\%)\end{array}$ & $\begin{array}{c}\text { Damaged } \\
\text { starch } \\
(\%)\end{array}$ \\
\hline Koshihikari & 90.3 & 3.2 & 1.2 & 14.4 \\
\hline Hokuriku 166 & 89.6 & 5.4 & 1.3 & 10.1 \\
\hline Hokuriku 169 & 88.4 & 23.3 & 4.3 & 93.5 \\
\hline
\end{tabular}

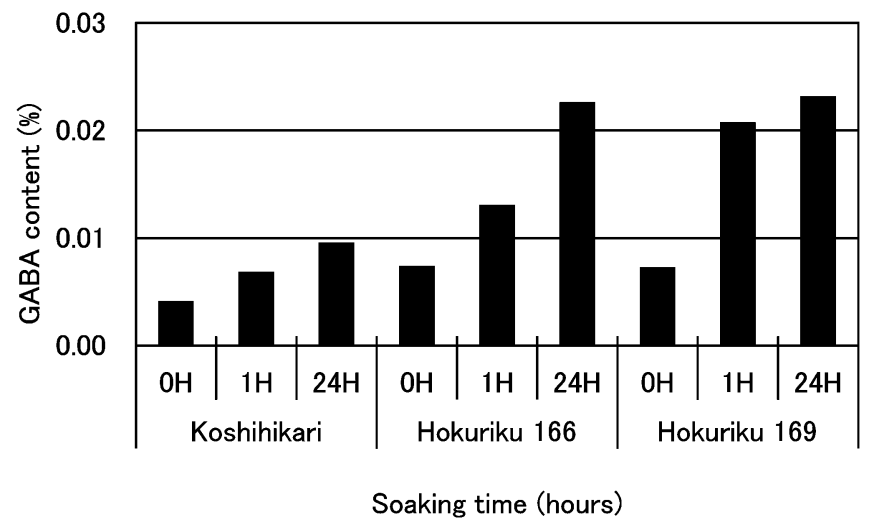

Fig. 1. The GABA contents from the rice cultivars soaked in water during 0-24 hour.

Table 3. Distribution of particle size for Koshihikari and Hokuriku 166.

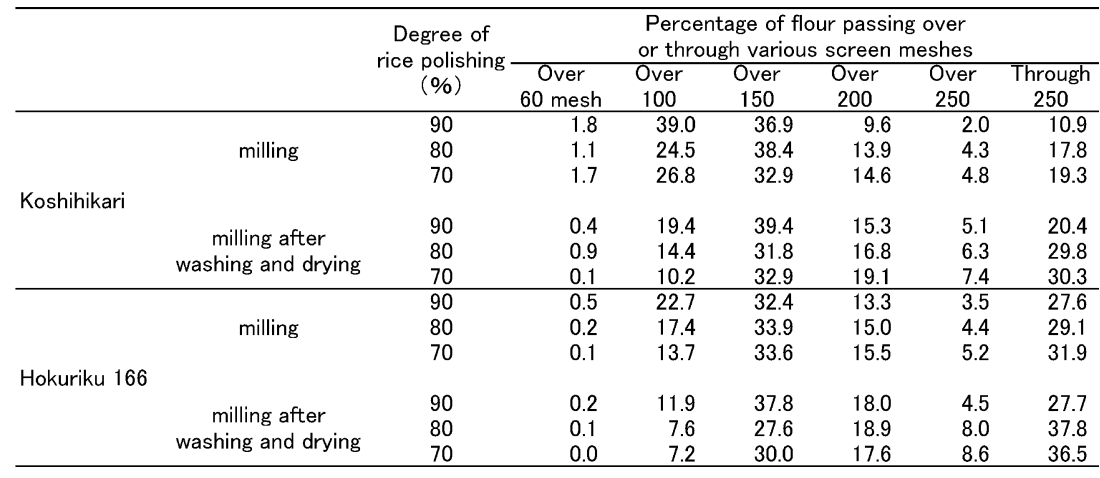


Table 4. Brabender viscogram parameters.

\begin{tabular}{lccccccc}
\hline \multicolumn{1}{c}{$\begin{array}{c}\text { Degree of } \\
\text { rice } \\
\text { polishing } \\
(\%)\end{array}$} & $\begin{array}{c}\text { GT } \\
\left({ }^{\circ} \mathrm{C}\right)\end{array}$ & $\begin{array}{c}\text { PV } \\
(\mathrm{BU})\end{array}$ & $\begin{array}{c}\text { MV } \\
(\mathrm{BU})\end{array}$ & $\begin{array}{c}\text { FV } \\
(\mathrm{BU})\end{array}$ & $\begin{array}{c}\mathrm{BD} \\
(\mathrm{BU})\end{array}$ & $\begin{array}{c}\text { SB } \\
(\mathrm{BU})\end{array}$ \\
\hline Koshihikari & 100 & 69.0 & 590 & 280 & 740 & 310 & 460 \\
& 90 & 70.0 & 775 & 340 & 790 & 435 & 450 \\
& 80 & 69.0 & 890 & 380 & 840 & 510 & 460 \\
& 70 & 67.5 & 910 & 380 & 850 & 530 & 470 \\
\hline Hokuriku 166 & 100 & 72.0 & 230 & 130 & 480 & 100 & 350 \\
& 90 & 66.0 & 320 & 180 & 550 & 140 & 370 \\
& 80 & 67.5 & 420 & 235 & 680 & 185 & 445 \\
& 70 & 67.5 & 480 & 260 & 720 & 220 & 460 \\
\hline Hokuriku 169 & 100 & - & 0 & 0 & 50 & 0 & 50 \\
& 90 & - & 0 & 0 & 50 & 0 & 50 \\
& 80 & - & 0 & 0 & 60 & 0 & 60 \\
\hline Abbreviations: GT, gelatinization temperature; PV, peak viscosity, MV, minimum viscosity:
\end{tabular}

FV, final viscosity; BD, break down; SB, set back viscosity

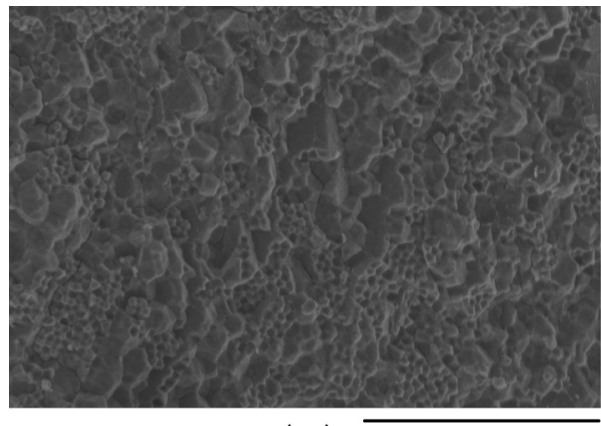

(a)

$100 u m$

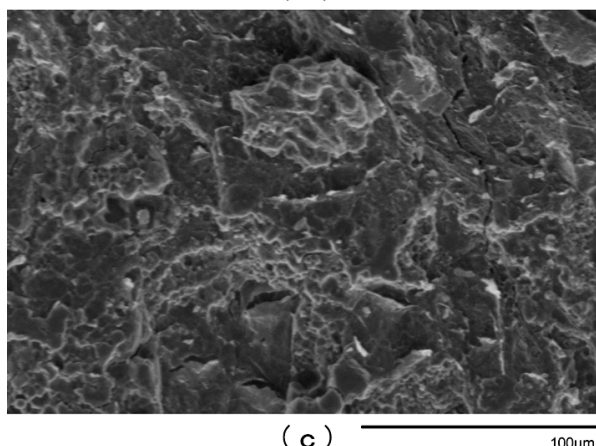

(c)

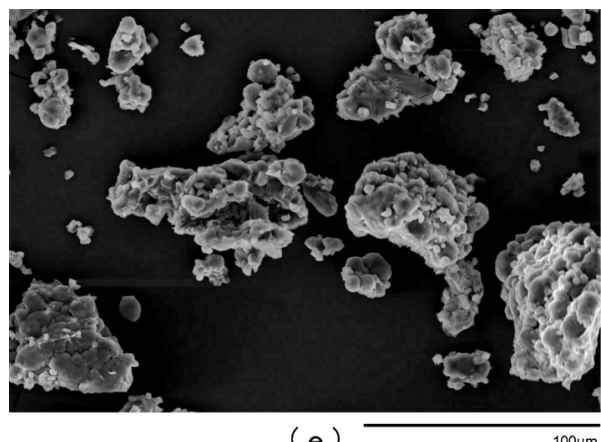

(e )

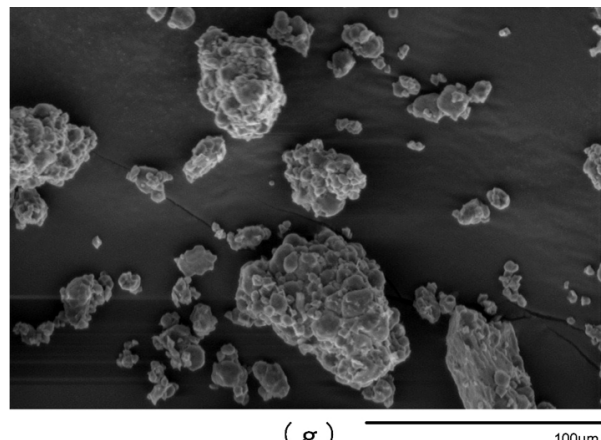

( g ) ticle sizes of Koshihikari and Hokuriku 166 are shown in Table 3. In this case, particles of rice flours which passed through 200 mesh are described as fine. The fineness of rice flour increased when the outer part of the rice is reduced. Furthermore, the degree of the fineness of Hokuriku 166 was higher than Koshihikari, when compared at each polishing stage. When each rice cultivar was milled after washing and drying, an increase in fineness was observed. In addition, Hokuriku 166 was composed of smaller particles than those of Koshihikari, thus the difference between the fineness of Hokuriku 166 and Koshihikari did not change.

Brabender viscogram The pasting properties of Koshi-

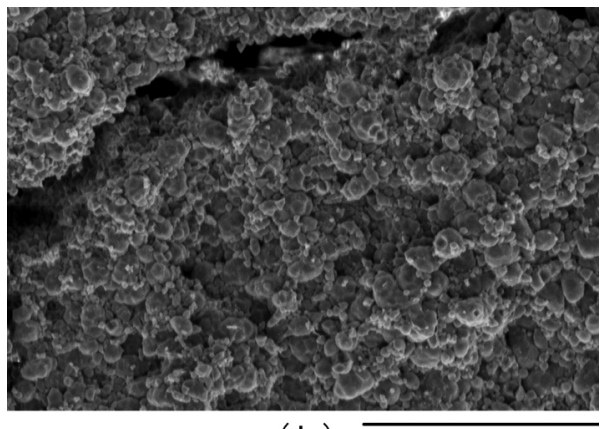

(b)

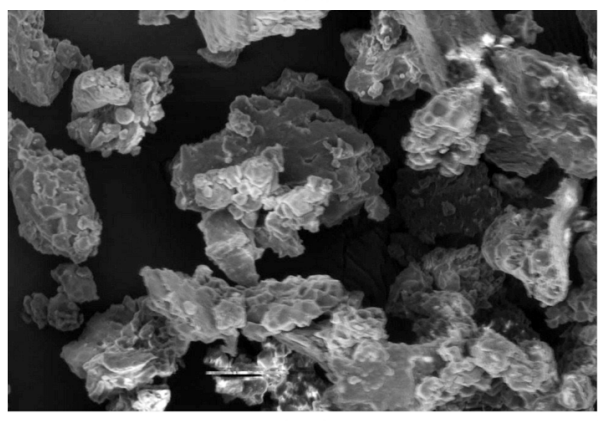

(d)

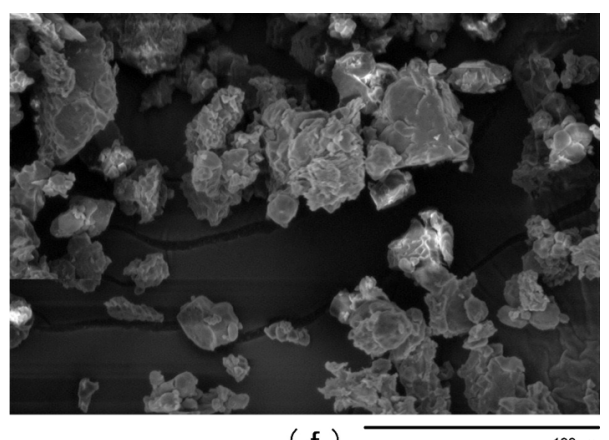

( f )

$100 \mathrm{um}$

Fig. 2. Microstructure of cross section and particles from rice cultivars.

Cross section: (a) Koshihikari; (b) Hokuriku 166; (c) Hokuriku 169.

Particles of the pulverized rice: (d) Koshihikari; (e) Hokuriku 166.

Particles of the pulverized rice after the washing and drying; (f) Koshihikari; (g) Hokuriku 166. 
hikari, Hokuriku 166, and Hokuriku 169 are summarized in Table 4. Almost all the values of peak, minimum, final, breakdown and setback viscosity had a tendency to increase with increased polishing of the rice grains. When compared with Koshihikari, Hokuriku 166 tended to be low in viscosity although equivalent in gelatinization temperature. In contrast, Hokuriku 169 had unique pasting properties and its viscosity in gelatinization was very low. In particular, the peak and minimum viscosities could not be measured. The pasting properties of sugary mutant rice have previously been reported (Wong et al., 2003), with low viscosity observed. The results of Hokuriku 169 viscosity was supposed not starch but that it is reflects the effect of the quantity of phytoglycogen as mentioned by Asaoka et al., (1985).

Scanning electron micrograph (SEM) analysis The SEM images of the shape and cross section of particles (through 250 mesh) are shown in Fig. 2. The cross section of Hokuriku 166 (b) appeared to be more of a regular granule shape, whereas Hokuriku 169 (c) had an appearance more similar to the sticky shape than that of Koshihikari (a). While Koshihikari appeared solid and full, Hokuriku 166 was loosely packed and had many gaps. Therefore, based on the structure of Hokuriku 166, it is assumed that the conversion of glutamic acid into GABA under the presence of water (Fig. 1) was facilitated by the water. The crack seems to facilitate the pulverization of Hokuriku 166. Regarding the particles (through 250 mesh), after polishing until $90 \%$ of the yield and pulverization, differences in granule shape were observed between Koshihikari (d) and Hokuriku 166 (e). The Koshihikari particles were jagged, whereas those of Hokuriku 166 were globular. Furthermore, the surface of Koshihikari starch granules was rough, but the surface of Hokuriku 166 starch granules was smooth. When milled after washing and drying, the shape of the particles (f, $g$ ) tended to be the same. The shape of these particles seems to have a large effect on the characteristics and quality of the powder.

From the results obtained in this paper, it is concluded that Hokuriku 166 and 169 had characteristic properties comparable with Koshihikari. In particular, the fineness of Hokuriku 166 rice flour and the component parts of Hokuriku 169 are promising as raw material for processing.

It is easy to make fine rice flour using Hokuriku 166 since the starch granule particles are globular and small, and since there are many interparticular gaps in the grain. Such rice particles are highly expansive in pasting starch granules using heat; therefore, they are easy to handle. Hokuriku 169, the sugary mutant, has the highest proportion of bran, and the GABA content is also high. Therefore, it is expected to be utilized not as rice flour but as raw material, for example, for fermentation.

Further detailed studies of the properties of Hokuriku 166 and 169 , such as the processing characteristics, are now under way in our research center.

\section{References}

Arisaka, M. and Yoshii, Y. (1994). Properties of high-amylose rice starch paste. Oyo Toshitsu Kagaku, 41, 1-7.

Arisaka, M. (1994). Studies on evaluations of property of starch in the manufacturing process of rice cracker. Niigata-ken Shokuhin Kenkyuzyo Hokoku., Special report (in Japanese).

Asaoka, M., Okuno, K., Sugimoto, Y., Yano, M., Omura, T. and Fuwa, H. (1985). Structure and properties of endosperm starch and water soluble polysaccharides from sugary mutant of rice (Oryza sativa L.). Starch, 37, 364-366.

Dubois, M., Gilles, K. A., Hamilton, J. K., Rebers, P. A. and Smith, F. (1956). Colorimetric method for determination of sugars and related substances. Anal. Chem., 28, 350-356.

Fuwa, H., Asaoka, M., Shintani, H., Shigematsu, T., Oshiba, M. and Inouchi, N. (1994). Properties of endosperm starch of new types of rice grains. Nippon Shokuhin Kogyo Gakkaishi, 41 (6), 413-418 (in Japanese).

Juliano, B.O. (1971). A simplified assay for milled-rice amylose. Cereal Sci. Today, 12, 334-360.

Kobayashi, A., Koga, Y., Uchiyamada, H., Samoto, S., Horiuchi, H., Miura, K., Okuno, K., Fujita, Y., Uehara, Y., Ishizuka, S., Nakagahra, M., Yamada, T. and Maruyama, K. (1990). Breeding a new rice variety "Oochikara" Hokuriku Nogyo Shikenjo Hokoku, 32, 85-104 (in Japanese).

Kobayashi, A., Koga, Y., Uchiyamada, H., Samoto, S., Horiuchi, H., Miura, K., Okuno, K., Fujita, Y., Uehara, Y., Ishizuka, S., Nakagahra, M. and Yamada, T. (1990). Breeding a new rice variety "Habataki". Hokuriku Nogyo Shikenjo Hokoku, 32, 65-84 (in Japanese).

Kobayashi, A., Koga, Y., Uchiyamada, H., Miura, K., Shimizu, H., Oota, H., Horiuchi, H., Okuno, K., Fujita, Y., Ishizaka, S., Uehara, Y., Nakagahra, M., Yamada, T., Watanabe, S., Matsumoto, S., Higashi, M., Noboru, H. and Akama, Y. (1992). Breeding a new glutinous rice cultivar "Minenoyukimochi". Hokuriku Nogyo Shikenjo Hokoku, 34, 87-109 (in Japanese).

Kobayashi, A., Suzuki, Y., Kobayashi, A., Miura, K. and Ohtsubo, K. (1998). Grain qualities of new-characteristic-rices developed in hokuriku district. Nippon Shokuhin Kogyo Gakkaishi, 45, 484-493 (in Japanese).

Kuno, M., Kainuma, K. and Takahashi, S. (2000). Physicochemical characteristics of low-amylose rice starches. J. Appl. Glycosci., 47 (3-4), 319-326.

Mizukami, H., Hizukuri, S. and Takeda, Y. (1996). Structures and pasting properties of starches from new characteristic rice cultivars. J. Appl. Glycosci., 43 (1), 15-23.

Noda, T., Nishida, Y., Sato, T. and Suda, I. (2003). Properties of starches from several low-amylose rice cultivars. Cereal Chem., 80 (2), 193-197.

Ohtsubo, K., Nakagahra, M. and Iwasaki, T. (1988). Utilization suitabilities of new endosperm characters of rice strains. Nippon Shokuhin Kogyo Gakkaishi, 35 (9), 587-594 (in Japanese).

Ohtsubo, K.(1995). In Science of Rice. Ishitani, T. and Ohtsubo, K., eds., Asakura Shoten, p.18. (in Japanease).

Toyoshima, H., Naito, S., Okadome, H., Baba, H., Murata, S., Ogawa., T and Ohtsubo, K. (1994). Evaluation of properties of the "New Characteristic Rices”. Rep. Natl. Food Res. Inst, 58, 27-36.

Toyoshima, H., Okadome, H., Yoshizaki, S., Kimura, T. and Ohtsubo, K. (1999). Evaluation of textural and chemical properties of newly bred characteristic rice grains. Nippon Shokuhin Kogyo Gakkaishi, 46, 123-130 (in Japanese).

Uehara, Y., Kobayashi, A., Koga, Y., Uchiyamada, H., Miura, K., Fukui, K., Shimizu, H., Ohta, H., Fujita, Y., Okuno, K., Ishizaka, S., Horiuchi, H. and Nakagahra, M. (1995). Breeding of a new rice cultivar "Dontokoi”. Hokuriku Nogyo Shikenjo Hokoku, 37, 107-131 (in Japanese).

Uehara, Y., Kobayashi, A., Koga, Y., Fukui, K., Shimizu, H., Ohta, H., Miura, K., Horiuchi, H., Okuno, K. and Fujita, Y. (1995). 
Breeding of low amylose rice cultivar "Soft 158". Hokuriku Nogyo Shikenjo Hokoku., 37, 133-153 (in Japanese).

Uehara, Y., Kobayashi, A., Koga, Y., Uchiyamada, H., Shimizu, H., Ohta, H., Fukui, K., Otsuki, H., Miura, K., Horiuchi, H., Okuno, K., Fujita, Y., Ishizaka, S., Nakagahra, M. and Yamada,T. (1997). Breeding of a high amylose rice cultivar "Yumetoiro". Hokuriku Nogyo Shikenjo Hokoku, 39, 23-47 (in Japanese).

Villareal, C. P. Maranville, J.W. and Juliano, B.O. (1991). Nutrient content and retention during milling of brown rices from the international rice research institute. Cereal Chem., 68 (4), 437439.

Wong, K.S.,. Kubo, A., Jane, J.L., Harada, K., Satoh, H. and Nakamura, Y. (2003). Structure and properties of amylopectin and phytoglycogen in the endosperm of sugary-1 mutants of rice. J. Cereal Sci., 37, 139-149.

Yamada, H., Sasagawa, N. and Kitazawa, K. (1993). Suitabilities of improved rice varieties and lines for rice crackers. Nippon Shokuhin Kogyo Gakkaishi, 40 (4), 278-286 (in Japanese). 